\title{
DE HERVATTING DER SURINAAMSCHE BACOVENCULTUUR
}

\author{
DOOR
}

W. R. MENKMAN

Toen indertijd besloten werd, de Surinaamsche bacovencultuur met gouvernementssteun (periode 1905-1913) te beeindigen, was het blijkbaar de bedoeling dat de liquidatie finaal en totaal zijn zou.

De United Fruit Company, verreweg de belangrijkste figuur in de bananenwereld, zoowel in als buiten Amerika, had de gelegenheid gehad, op voor haar gunstige voorwaarden, er zich van te overtuigen, of Suriname, destijds een land dat ver buiten de zone lag der bananencultuur voor uitvoer naar de Vereenigde Staten en Europa, al dan niet kansen bood, om aanplantingen van de Gros Michel-varieteit (de specialiteit der U.F.C.) vrij te houden van de elders groote verwoestingen aanrichtende $\mathrm{Pa}-$ namaziekte, tegen welke voorshands geen remedie te vinden was.

Het resultaat was negatief en de genoemde Amerikaansche onderneming trok zich terug, daarbij prompt haar verplichting nakomende, om de Surinaamsche bananenvloot op de in 1906 bij voorbaat gestelde voorwaarden over te nemen. Was er destijds eenige sprake van geweest, dat Regeering en Bestuur zich, ondanks de ondervonden teleurstelling, toch voor de bacovencultuur bleven interesseeren, als voor de toekomstige ontwikkeling van Suriname van groote beteekenis, dan zou men zeker het transportmiddel niet hebben mogen prijsgeven; contractueel bestond er geen verplichting tot dit laatste. Zelfs is de vraag gewettigd - al kan dan ook niemand die met eenige zekerheid beantwoorden - of de U.F.C. Suriname wel zoo gemakkelijk in den steek gelaten zou hebben, wanneer de tegenpartij in het bezit eener transportorganisatie ware gebleven, m.a.w. wanneer aan de Company te kennen ware gegeven, dat van de bevoegdheid om aan haar de vier Surinaamsche vruchtenschepen over te doen, geen gebruik zou worden gemaakt. 
Overigens zouden, wanneer er voorzien was dat de bacovencultuur te eeniger tijd wederom voor Suriname van belang zou kunnen zijn, verschillende vraagstukken, welke er zich aan vastknoopen, geen oogenblik uit het oog mogen zijn verloren en dan zou er thans allicht geen studie of onderzoek meer noodig zijn, om te kunnen vaststellen of, althans voor zoover betreft de in Suriname bestaande condities, hervatting der cultuur mogelijk is. De sedert het liquidatiebesluit van 1910 verloopen tijd lijkt ruimschoots voldoende, om alles te weten te komen wat er door studie en experimenteering op cultuurtechnisch en phytopathologisch gebied ter plaatse te leeren viel.

In 1912 voerde Suriname voor het laatst bacoven naar de V.S. uit, in 1913 gingen eenige proefzendingen naar Europa en in 1914 makkte de wereldoorlog voorloopig een einde aan de pogingen van particuliere zijde, om voor het product der nog in stand gebleven aanplantingen een afzetgebied te vinden, los van de U.F.C. en haar organisatie. Sedert heeft af en toe het vraagstuk der bacovencultuur wel weder eens de aandacht bezig gehouden, maar het heeft tot 1933 geduurd, voordat het opnieuw wat men noemt in het brandpunt der belangstelling is komen te staan.

$\mathrm{Na}$ hetgeen hierboven opgemerkt is aangaande het verloop der vorige bacovenonderneming, blijft er weinig reden bestaan voor de verwachting dat men thans vasteren grond onder de voeten zou hebben dan het geval was toen, in 1906, met de U.F.C. gecontracteerd werd; het tegendeel is zelfs eerder waar.

Destijds was men althans zeker van vervoer en afzet en was het risico voor Suriname beperkt tot de twee mogelijkheden dat $a$ ) de cultuur, in engeren zin, zou mislukken, of $b$ ) de voor tien jaar vastgestelde verkoopprijs zou blijken geen voldoende winst te laten. Thans zouden opnieuw oplossingen moeten worden gevonden, zoowel voor het vervoer- en het afzet- als voor het cultuurprobleem.

In 1905 werd het niet verantwoord geacht bacoven voor export te gaan produceeren, tenzij afzet in de V. S. verzekerd was en wel met de U.F.C. als koopster. Thans is de positie van genoemde Compagny nog altijd zeer sterk, hoewel natuurlijk ook zij aan concurrentie het hoofd heeft moeten bieden; geen verdediging behoevende monopolies bestaan nu eenmaal niet, ook in Yankeeland niet. In Haïti, een eiland zóó gunstig gelegen, dat versch tropisch fruit van daar, evenals van Cuba, Jamaica en Porto Rico, onafgekoeld naar de V. S. kan worden overgebracht, zijn ook bananen gekweekt voor export (zelfs Gros Michel-bananen), 
onafhankelijk van de U.F.C.-organisatie. Na een mislukking in 1930, werd een onbeduidende hoeveelheid naar New York verscheept in 1931, gevolgd door een wat grooter kwantum in 1932. Dat echter de U.F.C. en de in de V. S. in belangrijkheid op haar volgende Italiaansche onderneming een ook maar eenigszins aanzienlijk deel van haar terrein door de Haïtiaansche bananen veroverd zouden hebben gezien, heb ik niet gelezen en geloof ik ook niet; mede door haar sterke verkooporganisaties worden zij de natuurlijk telkens opduikende „outside competition" meestal spoedig de baas.

Intusschen is in de laatste decenniën de Europeesche markt voor tropisch fruit sterk in omvang toegenomen; men koopt tegenwoordig zelfs in de Zwitsersche bergen Westindische bananen. Voor deze vergrooting van debiet echter heeft vooral de U.F.C. zich ingespannen - of de combinatie waarin zij een belangrijke rol speelt - en dat op dit terrein een nieuwe concurrent zich niet zonder groote moeite, veel vakkennis en ruime middelen een plaats van eenige beteekenis zou kunnen veroveren, lijkt voor de hand te liggen. De levensgewoonten en de koopkracht van den consument in de Angelsaksische wereld hebben er niet weinig toe bijgedragen den afzet van bananen op te voeren tot het huidige peil; zoowel de V.S. als de Britsche eilanden evenwel gaan gebukt onder den ongunst der tijden en in beide gebieden is het betaalmiddel - in ongeveer gelijke mate - in waarde gedaald. Om van den toestand op het Europeesche vasteland niet te spreken.

Ook elders dan in de productielanden van weleer is de teelt van bananen voor export ter hand genomen. Brazilië en de Westkust van Afrika zijn, evenals Suriname, aangewezen op vervoer „in cold storage", liggen zelfs verder van de Europeesche markten verwijderd, maar verkeeren, wat scheepvaartverbinding betreft, in gunstiger omstandigheden.

Nederland ten slotte is nog geen bananenconsument van zeer groote beteekenis en zelfs aan de voorziening van deze markt heeft Suriname nog nimmer deelgenomen.

Alles bij elkander lijkt de tegenwoordige tijd niet bepaald bij uitstek geschikt voor een hervatting der meer dan twintig jaar geleden opgegeven Surinaamsche bacovencultuur.

Gegeven de economische impasse evenwel waarin onze Zuidamerikaansche vastelandskolonie ook thans weder is komen te verkeeren, is het alleszins verklaarbaar, dat die cultuur opnieuw in sterke mate de aandacht is gaan vragen. In één opzicht is 
de toestand nog dezelfde als vroeger; Nederland beschikt nog altijd niet over een overheidsorgaan dat zich bij voortduring met de economische vraagstukken, problemen en puzzles onzer Amerikaansche gebiedsdeelen - zoowel Curaçao als Suriname bezig houdt. Nog steeds verzamelen de deskundigen ter plaatse gegevens aangaande exploitatie, productie en kosten, maken zij berekeningen en werken zij op grond van die berekeningen plannen uit, maar het commercieele complement ontbreekt. Aangaande afzetmogelijkheden, marktposities, verkeerseischen en te bedingen prijzen, verkeeren de locale instanties natuurlijk in het duister, behalve voor zoover betreft de allernaaste omgeving. Dit geldt niet alleen ten aanzien van nieuwe cultures in Suriname (rijst, maïs, vruchten enz.), maar evenzeer met betrekking tot de kansen der zoutwinning op onze eilanden in de Caraibische Zee en een analoog gebrek aan coördinatie zal zich wellicht doen voelen, wanneer ter hand mocht worden genomen het probleem van nieuwe bestaansbronnen voor de bevolking dier eilanden, uit land- en tuinbouw, veeteelt, bodemontginning en inheemsche industrieën ${ }^{1}$ ).

Wat nu betreft de Surinaamsche bacovencultuur geeft het brochuretje „Een levensbelang voor Suriname”, uitgegeven door de redacties van „Suriname” en „De West" te Paramaribo een overzicht van den stand van zaken; het bevat de verhandelingen in de Koloniale Staten over het onderwerp in kwestie - met eenige supplementen - en is een bespreking alleszins waard.

Op 24 April 1933 deden vier, wel en niet bij den landbouw belanghebbende personen een voorstel aan den toenmaligen gouverneur, om - natuurlijk met gouvernementssteun - een oppervlakte van 1200 H.A. met bacoven (van de Congovariëteit, waarvan in het Koloniaal Verslag over 1912 verklaard werd dat zij immuun was gebleken voor Panamaziekte) te beplanten. Van deze oppervlakte zou de oogst voldoende zijn om wekelijksche verschepingen van 20.000 bossen mogelijk te maken; men meende dus op een opbrengst van $800 / 900$ bossen per H.A. per jaar te mogen rekenen. Het ligt voor de hand - en dat zullen de auteurs van het plan zelf ook wel hebben ingezien - dat de rentabiliteit eener bacovencultuur voor uitvoer staat en valt met de absolute mogelijkheid om geregeld passende scheepsgelegenheid te vinden voor de verzendingsrijpe vruchten, tegen een niet prohibitieve

1) Zie aangaande deze laatste het artikel van Ir. P. Cohen Henriquez in het avondblad van De Telegraaf van 22 December 1934. 
vracht en met de zekerheid van verkoop tegen loonenden prijs, ter plaatse van bestemming.

Opgemerkt moge worden, dat het contract met de U.F.C. van 1906 een jaarlijksche opbrengst voorzag van slechts 500 bossen (Gros Michel-bacoven) per H.A., maar dat in 1923 een vertegenwoordiger der zelfde U.F.C. oogsten van 360 bossen per jaar en per acre (bijna 900 bossen per jaar en per H.A.) voor Jamaica als normaal voorstelde ${ }^{1}$ ). Intusschen heeft de eerste onderteekenaar van het hooger genoemde ontwerp op een Surinaamsche plantage een daadwerkelijk resultaat verkregen, met een proefveld, van 1000 bossen (Congobacoven) per jaar per H.A. Een publicatie van de U.F.C. bevatte eens een plaatje van 1250 planten per manzano (0.7 H.A.), zes maanden nadat de knollen waren uitgezet ${ }^{2}$ ).

De gouverneur van Suriname in 1933 toonde zich een voorstander van het hervatten der bacovencultuur voor uitvoer, als een middel om den plantagelandbouw (d.w.z. de koffiecultuur) op een doeltreffender wijze te steunen, dan tot dusver geschiedde. De Liberiakoffie wordt geacht in Suriname zóó goed te gedijen, dat alleen de sedert een aantal jaren zeer lage prijs aan de rentabiliteit der cultuur in den weg staat, om welke reden zij door steun uit de openbare kas kunstmatig op de been gehouden wordt. Niettegenstaande dien steun neemt het aantal plantages af; zonder dien steun zou de plantagelandbouw ineenzakken. Niet meer in bedrijf zijnde plantages verwaarloozen snel (kapitaalvernietiging) en men wil den grooten landbouw in het leven houden, hoewel men er zich van bewust is, dat de cultuurgrond van verlaten plantages alleen voor de productie verloren gaat, voor zoover die grond niet door den kleinen landbouw geoccupeerd wordt. Het agrarische bevolkingsdeel dat zelfstandig den landbouw beoefent, heeft de neiging in getalsterkte toe te nemen en overtreft reeds lang het plantage-arbeid verrichtende gedeelte aanzienlijk.

De gouverneur bleek van meening, dat de thans voor steunverleening vereischte gelden nuttiger zouden kunnen worden besteed en met een betere kans op terugvloeiïng in de openbare kas, wanneer die gelden werden aangewend om aan de koffieplantages een winstgevende bijcultuur te verschaffen, waarvoor dan de bacovencultuur voor uitvoer bij voorkeur in aanmerking

1) Daily Argosy, Demerara, Sept. 71923.

$\left.{ }^{2}\right)$ Dr. R. Rung. Die Bananencultur. Petermanns Mitt. 1911. 
zou komen. Ook in de behoefte van den kleinen landbouw aan een exportproduct zou de bacoventeelt kunnen voorzien.

Een nota van 30 Juni 1933 bevatte een door den gouverneur uitgewerkt plan, om op bestaande plantages in twee jaar tijds 1400 H.A. met bacoven te beplanten. Van deze oppervlakte zouden in het eerste productiejaar 2 maal per 3 weken 10.000 bossen geoogst kunnen worden, in het tweede productiejaar 16.000 bossen per week en de tegenwoordige steun aan de koffiecultuur zou gaandeweg verminderd kunnen worden, naar mate inkomsten uit de bijcultuur verkregen zouden worden. De raming der opbrengst, nog geen 600 bossen per jaar en per H.A. van een voor de helft in vollen bloei zijnden aanplant, werd in Suriname als een conservatieve beschouwd.

Het ontwerp in kwestie hield zich, uit den aard der zaak, alweer voornamelijk met de cultuurmogelijkheden bezig, hoewel de landvoogd meende, dat volstaan zou kunnen worden met een over twee jaren verdeelde subsidie van een half millioen gulden. Tegenover deze betaling door het gouvernement zou de gegadigde het in cultuur brengen op zich moeten nemen en óók de organisatie van verscheping en verkoop, hij zou garantie moeten geven voor de richtige nakoming zijner verplichtingen en het risico moeten aanvaarden dat de te verschepen hoeveelheden beneden de raming zouden blijven. Dat hier slechts bloot een desideratum gesteld werd, zonder voldoenden grond voor de verwachting, dat een gegadigde te vinden zou zijn, bereid om de gestipuleerde voorwaarden te aanvaarden, is duidelijk.

In de Kol. Staten werd op 16 Augustus 1933 m.a.s. een motie aangenomen, waarin instemming met het plan betuigd werd; economisch gesproken, zoo werd betoogd, zou echter alleen een zeer spoedige hervatting der bacovencultuur beteekenis hebben en, gegeven den crisistoestand - zoowel van kleinen als van grooten landbouw - zou een lang uitstel funest zijn. Alsof die hervatting een oplossing ware, waarnaar men de hand maar heeft uit te steken, zoodra de nood aan den man is!

Een andere instantie, de Surinaamsche Landbouw Vereeniging, of althans haar bestuur, had bezwaren en achtte betere voorbereiding en voorafgaande proefnemingen - natuurlijk uitsluitend het cultuurvraagstuk betreffend - gewenscht; zij begon zelf met proefvelden aan te leggen.

In het najaar van 1933 ging de Surinaamsche landvoogdij in andere handen over en op 4 Mei 1934 werd in de K.S. een beroep gedaan op den nieuwen gouverneur, opdat deze zich de zaak 
der bacovencultuur ernstig zou aantrekken en daardoor zou bevorderen, dat de plantagelandbouw voor den ondergang behoed werd.

De beoordeeling van het plan van den afgetreden gouverneur intusschen, waarmede rijksgelden gemoeid waren, was natuurlijk bij den minister van Koloniën en deze legde het voor aan den Ondernemersraad voor Suriname, welke laatste in een in December 1933 uitgebracht advies instemming met het principe betuigde en een nadere uitwerking toezegde. Voordat deze laatste gereed was, werd uit Suriname het optreden eener bladziekte in de proefaanplantingen gerapporteerd. Niettemin had de nadere uitwerking voortgang en er kwam een project tot stand, dat door den genoemden Raad aan de S.L.V. ter fine van advies werd voorgelegd, maar, onder de bestaande omstandigheden, slechts als een theoretisch plan mocht gelden.

Dit theoretische ontwerp was tevens een grootsch ontwerp, in zooverre dat het voorzag in een beplanting van 3200 H.A. met bacoven, in het in de vaart brengen van schepen met een vervoercapaciteit van 50.000 bossen en in een verkooporganisatie; er zouden ettelijke (hoevele?) millioenen kapitaal mede gemoeid zijn. Als vrachtcijfer werd gecalculeerd 60 cents per bos, als verkoopprijs voor den planter eveneens 60 cents en als opbrengst (in Europa) $f 1.75$ per bos. Of dit ontwerp niet ook met betrekking tot verscheping en afzetmogelijkheid een theoretisch ontwerp was - om van kapitaalvoorziening en rentabiliteit niet te spreken, tenzij er uitsluitend aan overheidsbeheer gedacht werd lijkt geen geheel en al ongemotiveerde vraag.

Hierbij moge opgemerkt worden, dat het oude U.F.C.-contract wekelijksche verschepingen voorzag (naar New York, half zoover van Suriname verwijderd als de Noordwesteuropeesche havens) en dat voor dezen dienst, gegeven afstand en vaartsnelheid, met drie schepen amper volstaan had kunnen worden, d.w.z. voor een regelrechten dienst Paramaribo-New York vice versa, zonder oponthoud onderweg. Ten einde echter in de behoefte aan een reserve te voorzien en om in het normale vaarplan tusschenhavens te kunnen aandoen (lading voor andere bestemmingen op de reis naar Paramaribo en bijlading van andere afscheephavens op de reis van Paramaribo) werden vier schepen in de vaart gebracht, waarvan destijds (1907) de bouwsom per schip om en bij een millioen gulden bedroeg. Deze speciaal voor den vereischten dienst gebouwde schepen waren natuurlijk van zoodanig charter, dat zij toegeladen nog juist de 
laad- en losplaatsen aan de Surinamerivier bereiken konden, doch de ladingruimte was slechts voor $2 / 3$ voor het vruchtenvervoer ingericht, in verband met de - zooals wij gezien hebben lage - raming der opbrengst van de in cultuur te brengen 3000 H.A., t. w. circa 30.000 bossen per week. Projecteert men thans schepen met een capaciteit van 50.000 bossen, dan lijkt de veronderstelling niet gewaagd, dat men het oog heeft op vaartuigen waarvan de ladingruimte voor $100 \%$ op vruchtentransport ingericht is, tenzij men op kleine bossen rekent. Deze laatste veronderstelling zou-steun vinden in de mededeeling van den O.R. dat het gewicht van een bos op 16 K.G. gesteld kan worden, wat geen hoog cijfer is, vergeleken bij hetgeen een „full bunch” Gros Michel weegt. Waar dan echter weder tegenover staat, dat de G.M. voordeeliger stuwt dan eenige andere soort ${ }^{1}$ ).

Ook aan de hand van deze gegevens blijft een gissing naar het aantal millioenen dat het groote project van den O.R. alleen reeds voor de aanschaffing van schepen zou eischen, nogal speculatief; men zou allereerst moeten weten welke frequentie van afvaarten de Raad zich gedacht heeft. Bekende factoren echter zijn de volgende: dat, al het overige gelijk staande, voor de vaart op Europa niet ten volle twee maal zooveel schepen noodig zijn, als voor die op New York (het oponthoud in de havens speelt op een langere reis een kleinere rol dan op een kortere), dat altijd en overal een grootere tusschenruimte dan een week tusschen twee verschepingen van bananen een bezwaar wordt geacht, dat de hoeveelheid lading naar en van Suriname, buiten en behalve de hypothetische bananen, zeer gering is en dat de gelegenheid voor het bedienen van tusschenhavens (zie de kaart) op het traject Suriname-Europa minder gunstig is dan op het traject Paramaribo-New York. Dit alles ook om te geraken tot een, zij het dan oppervlakkige waardeering van het vrachtcijfer, dat op de reis naar Europa hoogstens te besommen zou zijn, t.w. 30.000 gulden.

Hoewel de bacovencultuur onder contract met de U.F.C. geschiedenis geworden is, acht ik mij toch niet gerechtigd, de destijds geldende vervoerovereenkomst te publiceeren. Wanneer ik echter de vrachtcijfers vergelijk, dan kan ik tot geen andere conclusie komen dan deze, dat, alle omstandigheden in aanmerking genomen, de door den O.R. gecalculeerde vracht den vervoerder allerminst betere kansen geeft dan de vracht van des-

$\left.{ }^{1}\right)$ Empire marketing board; publication January 1391. 
tijds. Toch zou de toenmalige dienst - welke, bij voortdurend gebrek aan volle vruchtenladingen, groote verliezen heeft opgeleverd - ook in het gunstigste geval nauwelijks winstgevend zijn geweest; de marge tusschen hetgeen maximaal besomd worden kon en het door de U.F.C. gegarandeerde minimum, was niet groot.

Wat géén geheim is, dat is de toenmaals door de U.F.C. betaalde prijs voor de bacoven; oudere Surinaamsche planters zullen zich de cijfers nog wel herinneren, t.w. 20, 30 of 35 cents (American gold), naar het seizoen, voor eerste soort, voor tweede soort de helft tot twee derden van den prijs voor eerste soort, voor derde soort, wanneer de Company daarop reflecteerde, de helft. Er is destijds wel eens aan getwijfeld of de cultuur, gegeven de genoemde verkoopprijzen, wel rendabel zou geweest zijn, al ware zij technisch geslaagd. De U.F.C. legde al haar gezag in de weegschaal, om te voorkomen dat de opbrengst van 500 bossen per jaar per H.A. overschreden werd en de dankbare Surinaamsche bodem reageerde prompt, d.w.z. dat de wijd uiteen geplante stoelen prachtige bossen produceerden, waarvoor nimmer meer dan de voor eerste soort (,nine hands") vastgestelde prijs werd genoten en welke ongeschonden afgeleverd moesten worden. Of de door den O.R. gecalculeerde prijs van 60 cents (Nederlandsche munt), in Suriname, een hooge of een lage is, hetzij voor den kooper of voor den verkooper, hangt wel in de eerste plaats af van de eischen welke aan het product gesteld zouden worden. Afgezien nog van de varieteit, is „bos” of "tros” een nogal vaag begrip.

De bij import in Europa te bedingen prijs van $f 1.75$ per bos is gebaseerd op een gewicht van 16 K.G., tegen 11 cents per K.G. Volgens den O.R. was (eind 1934) de Europeesche markt gedemoraliseerd (afzetmoeilijkheden in Duitschland, contingenteering in andere landen) en de prijs daardoor gedaald tot het ongekend lage peil van 7 à 8 cents per K.G., tegen twee à drie maal zooveel in vroeger jaren. Inderdaad, ik heb een nota vóór mij liggen van Juli 1930, van een Nederlandsche importzaak, die uitsluitend „Fyffes”-bananen leverde en destijds aan den winkelier 55 cents per K.G. berekende. Natuurlijk koopt een „importeur" hier te lande (regelrecht?) van de buitenlandsche onderneming, die de lading uit het productieland ontvangt en hebben wij dus in ieder geval te maken met een eerste hand (de werkelijke importeur) en een tweede (de grossier); de bruto winst van laatstgenoemde is allicht niet onaanzienlijk, want hij 
heeft, evenals de winkelier, risico van bederf en, procentsgewijze, hooge kosten. Thans (Januari 1935), betaalt men in den winkel 25 cents voor een Kilo niet zoo heel mooie bananen.

In ieder geval blijken de prijzen, waartegen uit het schip verkocht wordt, sterk te fluctueeren; in de V.S. is dit eveneens het geval. De U.F.C. en de in belangrijkheid op haar volgende bananenonderneming te New York, verkoopen de in afgekoelde scheepsruimte en dus met een zeer gering risico van bederf overgevoerde vruchten liefst zeilende en verder hebben zij eigen verkooporganisaties, over groote consumptiegebieden verspreid. En ten slotte hebben te New York nog veilingen aan boord plaats, direct na aankomst van schepen welke onafgekoelde bananen aanvoeren. De prijsschommelingen worden beheerscht door de invloeden van seizoen, aanvoeren en concurrentie. Toch konden indertijd aan de Surinaamsche planters de prijzen voor tien jaar gegarandeerd worden, waarbij dan met belangrijke commercieele risico's voor de Company rekening gehouden moet zijn.

Dat er ook in Europa aan den verkoop zeer veel vast zit, dat de commercieele aangelegenheid ook in de goede tijden een ingewikkelde is, mag veilig worden aangenomen. Hoe zou de gedemoraliseerde Europeesche markt zich gedragen, wanneer om dit geval nu maar eens te stellen - in Suriname enkele jaren geleden de cultuur van bacoven op eenigszins groote schaal ware hervat en thans van daar ladingen van $30.000-50.000$ bossen arriveerden?

Intusschen staat nu wel vast, dat ook over eenige jaren de Surinaamsche bacoven niet in zulke hoeveelheden op de Europeesche markten geintroduceerd zullen worden, want bij den O.R. is het groote plan voorloopig van de baan. In het laatst van het vorige jaar bleek, dat de Raad het vooralsnog niet verantwoord achtten, gegeven de opgetreden bladziekte en met het oog op sommige nog onopgeloste cultuurtechnische vraagstukken, het theoretische en omvangrijke plan aan de orde te stellen en deze organisatie daarom gekomen was tot een "tusschenplan". Dit kleinere plan komt neer op het huren van 150 H.A. plantagegrond, welke oppervlakte, vermeerderd met $50 \mathrm{H}$.A. van den kleinen landbouw en met de reeds aangelegde proefvelden $( \pm 30$ H.A.) bestemd zouden worden voor beplanting met bacoven, onder de leiding van een landbouwingenieur en twee landbouwkundigen. Voor het transport zouden in drie van de vier thans in de vaart zijnde stoomschepen koelruimten kunnen worden ingericht, met een capaciteit van 5000 bossen per schip, kosten 
130.000 gulden. De Surinamedienst, waarin deze schepen varen, is een driewekelijksche en, aangezien een van de vier niet voor het bacoventransport ingericht zal kunnen worden, zou, na aanvang der productie, telkens na drie afvaarten een tusschenruimte van zes weken ontstaan. Op deze wijze werkende meent men in 1938 voldoende ervaring opgedaan te kunnen hebben, om op de vraag of een hervatting der bacovencultuur op groote schaal kansen biedt, een beslist antwoord te kunnen geven.

Dit nieuwe ontwerp vond in het Surinaamsche vertegenwoordigende lichaam niet wat men mag noemen een gunstig onthaal en dat is begrijpelijk; de Staten waren door het "groote" plan van den O.R. met nieuwe hoop bezield geworden, de gouverneur had reeds studiecommissies benoemd en nu bleek dat men zich met een doode musch verblijd had.

In de zitting der K.S. van 29 Nov. 1934 werden al de nadeelen van het „tusschenplan" in het licht gesteld; het zal de beslissing betreffende de hervatting der bacovencultuur op groote schaal tot 1938 opschorten, het zal allicht even kostbaar zijn als het gouvernementeele plan van 1933, de bestaande plantages zullen niet direct zelfstandig aan de cultuur deelnemen en de verschepingen zullen met onvoldoende regelmatigheid en frequentie plaats hebben.

Bij dit alles werd, dunkt mij, uit het oog verloren, dat het plan van 1933 een half plan was ( het liet de verschepings- en de afzetaangelegenheid in het midden) en het groote plan van 1934 een theoretisch, een papieren plan. Dat de kosten verloren zullen zijn, wanneer er van hervatting op groote schaal niets komt, spreekt van zelf; wij hebben thans met een proefneming te doen evenwel en proeven kosten altijd geld. Dat, bij driewekelijksche, respectievelijk zeswekelijksche verzending, fruit verloren zal moeten gaan, speelt principieel geen rol, omdat de proef welke men nemen wil, andere vraagstukken moet oplossen, dan dat der meest economische verscheping. De bestaande koffieplantages worden reeds gesteund en zullen natuurlijk steun moeten blijven genieten tijdens de proef met de bacovencultuur, wil men die bedrijven niet laten verdwijnen; zouden zij ook door welslagen der proef niet gebaat kunnen worden, dan behoefde die proef niet genomen te worden, want wij moeten aannemen, dat het nog steeds in de allereerste plaats gaat om den bestaanden grooten en niet b.v. om den kleinen landbouw.

Eén belangrijk punt kwam in de discussies van 29 November naar voren; wanneer in de komende periode de levensvatbaar- 
heid eener hervatte bacovencultuur op grootere schaal blijkt, zoo zegt men, dan zullen de millioenen kapitaal welke daarvoor noodig zullen zijn, verschaft worden. Bestaat dienaangaande wezenlijk zekerheid en hebben de belanghebbenden bij den plantagelandbouw de kans, dat de tegenwoordige omstandigheden, waaronder het bedrijf, ondanks den steun, langzaam dood dreigt te bloeden, binnen enkele jaren plaats zullen maken voor een veel gunstiger situatie, die van met een nieuw uitvoerproduct in behoorlijken doen te geraken, dan is er voor hen alle reden tot tevredenheid. Hun wordt dan meer geboden dan zij, in aanmerking genomen den tegenwoordigen toestand van den tropischen landbouw in het algemeen - en de mérites der bacovencultuur nuchter beoordeeld - eigenlijk verwachten konden.

De zitting der Staten werd besloten met het aannemen eener motie, ditmaal met op één na algemeene stemmen, waarbij er op aangedrongen werd, dat Regeering en Bestuur het gouvernementeele plan van 1933, al dan niet gewijzigd naar de omstandigheden, opnieuw in overweging zouden nemen.

Met een enkel woord werd in de Statenvergadering van 29 November gewag gemaakt van een Deensche reederij, die bacoven ,,in cold storage” zou vervoeren van Brazilië naar Europa en vruchten (welke?) van Martinique en Guadeloupe naar Frankrijk, alsook zich interesseeren zou voor een (toekomstige) bacovencultuur in Fransch Guyana. Op 4 Dec. 1934 wendden een viertal personen zich tot den gouverneur, met de mededeeling, dat een vertegenwoordiger dier reederij een „aanbieding” zou gedaan hebben, om voor passende scheepsgelegenheid te zorgen, telkens wanneer er $3000-5000$ bossen bananen te verzenden zullen zijn en, minstens één maal per twee weken Suriname te doen aanloopen. Zij zou ,zeer milde” bepalingen willen toepassen ten aanzien van foutvracht wegens gemankeerde verschepingen en dat zij een zekere „bemiddeling” zou willen verleenen, bij den afzet in Europa, zou „niet uitgesloten” schijnen. De requestranten meenden dat thans de vicieuze cirkel als verbroken mocht worden beschouwd, een opvatting welke rijkelijk optimistisch lijkt.

Stelt men het bacoven vraagstuk van thans tegenover dat van 1906, dan treedt een eigenaardige tegenstelling naar voren; destijds bood een onderneming met een domineerende positie op de grootste bananenmarkt der wereld aan, de Surinaamsche bacoven gedurende tien jaar ter plaatse tegen een vasten prijs te koopen, doch zij behield zich het recht voor, zich terug te trek- 
ken, wanneer Suriname haar kwantitatief of kwalitatief niet leverde wat zij noodig had, thans is er getracht moeten worden, een onderneming of combinatie te vinden, in staat en bereid hetzelfde te doen, wanneer gebleken zal zijn dat Suriname marktwaardige bacoven in zekere hoeveelheden geregeld kan produceeren. Een bestaande bacovencultuur was er destijds niet en is er ook thans niet.

De geschiedenis der banaan, als consumptieartikel buiten de tropen, is een roman, welke geacht worden kan aangevangen te zijn met de bemoeienissen van Captain Lorenzo D. Baker van Boston, met de bananen van Jamaica, omstreeks 1870 en met die van Sir Alfred Lewis (destijds nog eenvoudig Mister) Jones, van Liverpool, met de bananen der Canarische eilanden, een tiental jaren daarna. Thans leven wij een halve eeuw later en wanneer men wil trachten Suriname, door middel der bacovencultuur, economisch te verheffen, dan moet men beginnen met over de techniek en de organisatie te beschikken, welke de pioniers langzamerhand verkregen hebben; dan moet men iets uit den grond stampen, wat elders langzaam is kunnen groeien. Het daaraan verbonden groote risico echter zal - mutatis mutandis - eveneens aanvaard zijn moeten worden, met betrekking tot de thans reeds zeer aanzienlijke Braziliaansche bananencultuur.

Wat in 1906 de U.F.C. gedaan had weten te krijgen, dat zij, voor zoover de cultuur en de levering betreft, met niemand anders dan met het Surinaamsche gouvernement te maken zou hebben, dat zal ongetwijfeld ook geeischt worden door den gegadigde voor het nieuwe product; dit in aanmerking genomen, zal de hervatting der cultuur niet uitsluitend een particuliere, commercieele aangelegenheid zijn, maar een van openbaar belang. Zooals trouwens het geheele Surinaamsche economische probleem, een aangelegenheid van openbaar belang is.

Zonder den prikkel van overheidssteun en overheidsgaranties, zou het vraagstuk der hervatting van de Surinaamsche bacovencultuur voor de zakenwereld moeilijk van belang kunnen zijn, tenzij een der volgende omstandigheden aanwezig was:

$1^{\circ}$ Suriname geacht zou kunnen worden een bepaalde markt goedkooper te kunnen voorzien dan eenig ander productieland,

$2^{\circ}$ sterke vermindering van productie in andere gebieden te verwachten zou zijn; men denke aan de Panamaziekte, welke zich voor het eerst in 1903 geopenbaard heeft, in de Gros Michel aanplant in Centraal Amerika, 
$3^{\circ}$ snelle vermeerdering van consumptie tegemoet gezien zou mogen worden, hetzij uit natuurlijke oorzaken, hetzij omdat het publiek blijk zou hebben gegeven, tot grootere consumptie „opgevoed" te kunnen worden,

$4^{\circ}$ een bepaald afzetgebied voor Surinaamsche bacoven gereserveerd zou kunnen worden; ten slotte zou Nederland eigen koloniale producten kunnen gaan beschermen, doch het is de vraag of de eigen, moederlandsche consumptie van bacoven, hoewel de import in 1930 bijna driemaal zoo groot was als in 1920, alléén een werkelijk belangrijke exportcultuur in Suriname op de been zou kunnen houden.

Particulier kapitaal en particulier initiatief zullen ook geen andere nieuwe cultures in Suriname tot stand brengen, wanneer niet een der hier genoemde factoren zich doet gelden; men bedenke echter, dat de banaan in Europa geen levensbehoefte is, maar een ,fancy"'-artikel.

De hervatting der bacovencultuur in Suriname zal natuurlijk slechts door gouvernementssteun mogelijk gemaakt kunnen worden en dat stempelt reeds bij voorbaat de onderneming tot een geforceerde, wat op zich zelf volstrekt niet met een veroordeeling gelijk behoeft te staan. Wil men het doel, dan moet men ook het middel willen; wanneer men dan de dingen maar nuchter blijft zien en er zich rekenschap van geeft, dat begonnen moet worden met uitgaven te doen, welke later misschien zullen blijken ook al weder onproductief te zijn geweest.

Amsterdam Januari 1935. 